\begin{tabular}{lc}
\hline \\
Sharif University of Technology \\
Scientia Iranica \\
SCIENTIA & Transactions B: Mechanical Engineering \\
I RAN ICA & \\
\hline
\end{tabular}

\title{
Investigation of transient numerical simulation of solidification and thermal behavior of metal molds with conformal cooling channels
}

\author{
O. İpek, A. Bolattürk, M. Kan*, and K. Kurtuluş \\ Department of Mechanical Engineering, Faculty of Engineering, Suleyman Demirel University, Isparta, Turkey. \\ Received 8 May 2018; received in revised form 21 July 2018; accepted 20 August 2018
}

\author{
KEYWORDS \\ Metal mold; \\ SLM; \\ Conformal cooling \\ channels.
}

\begin{abstract}
The cooling process in metal molds is one of the important factors in the solidification process of molten metal. Molding defects, such as hot spot defects and warping, are usually present in cast products when cooling is not uniform. However, qualified and faster cooling positively affects product quality. Molding is one of the important processes both in terms of cycle time and product quality, with permanent mold casting, high-quality liquid metal casting, and quality product. Selective Laser Melting (SLM) method was used to design metal mold cores with unique cooling channels to be compactly produced. The effects of the designed cooling channels, heat transfer, and solidification of the molten metal are studied in transient numerical terms. The temperature distributions at the 1 st, $3 \mathrm{rd}$, and 5 th seconds after casting were obtained, and the solidification processes were investigated according to the standard cooling channels of the original cooling channels. According to the results obtained, it was observed that solidification would function better in the originally designed cooling channels.
\end{abstract}

(C) 2019 Sharif University of Technology. All rights reserved.

\section{Introduction}

The cooling process in metal molds is one of the important factors in the solidification process of molten metal. Molding defects, such as hot spot defects and warping, occur in cast products when cooling is not uniform. However, qualified and faster cooling affects product quality positively. Molding is one of the important processes both in terms of cycle time and product quality, with permanent mold casting, high-quality liquid metal casting, and quality product. One of the permanent mold casting methods is metal gravity die casting, which is the casting of molten metal by a mold made of steel. Molding is one of

\footnotetext{
*. Corresponding author.

E-mail address: mehmetkan@sdu.edu.tr (M. Kan)
}

doi: $10.24200 /$ sci. 2018.50988 .1953 the important processes in terms of cycle time and product quality such that permanent mold casting produces high-quality product by casting liquid metal at high temperatures. There are many important problems in classical molding methods where the cooling process is performed by using vertical and horizontal channels formed on the mold body; these important problems such as deterioration and shrinkage of the obtained products arise because the cooling process cannot be homogeneous and sufficient. Therefore, the production period increases, which increases the cost of the product [1]. This is particularly important for parts with high production costs per unit volume (as in the medical, aerospace, space, energy, electronics, and automotive sectors). In recent years of work and developing technology, SLM (Selective Laser Melting) has been shown to be able to produce high-quality metal parts in a shorter production time period than conventional production methods [2-4]. In their stud- 
ies, the molds produced by the conventional method and the conformal injection molds produced by joint manufacturing for 2 different products are economically comparable [5]. It is emphasized that, in the near future, joint manufacturing will dominate other manufacturing methods in mold production. The mold, which can be produced by the joint manufacturing method, makes it possible to construct a complex cooling channel structure of a serial production mold. It has been proved by theoretical and experimental studies where a more uniform heat transfer takes place with appropriate cooling channels [6-9]. The fact that the cost of production is high in metal molds produced by an additive manufacturing method makes it necessary to produce the conformal cooling channel design with the desired performance. By applying the finite element method, the cooling performance of mold cooling channels and the solidification process of liquid metal can be simulated. Numerical studies point out the possibility of an increase in the cooling performance with a decrease in the solidification time through the conformal cooling channel [10-16]. Conformal cooling channels for the plastic injection mold design and the numerical and experimental cooling performance were examined. Numerical analysis and experimental results are consistent with each other and have a $12.8 \%$ shorter cycle time period with conformal cooling channels. In addition, Park and Dang [17] developed a conformal cooling channel for plastic injection mold. The results of this study showed $30 \%$ shorter cycle time with conformal cooling channels. In an experimental study, they have achieved an injection mold design with a conformal cooling channel through articulated manufacturing in a shorter time period compared to the mold regime temperature [18]. In order to reduce the cycle time in the aluminum metal injection mold (biscuit), the conformal cooling channel in the heel region was designed [19]. The numerical analysis and experimental verification showed that any increase in the cycle time of the original cooling channel with respect to the standard channel was observed. They achieved an increase in an extrusion rate of $300 \%$ by producing an aluminum extrusion die with conformal cooling channels with DMLS (Direct Metal Laser Sintering) [20]. According to the recent pieces of research, it was observed that the numerical analyses were verified with experimental studies. In this study, they carried out a timedependent numerical analysis of solidification melting behavior by using an enthalpy-porosity approach with ANSYS-FLUENT software for sodium nitrate in the case of thermal energy storage [21]. The results of the numerical analysis showed that the discharging process was slower than the charging process. It was suggested that engine parts, such as valves and camshafts, could be manufactured using aluminum alloys [22]. Numerical and experimental studies on aluminum and its alloys were carried out. Aluminum 6061-SiC MMCs (Metal Matrix Composites) were used to investigate the changes in their mechanical properties, microstructure, and hardness properties based on the ratio of $\mathrm{SiC}$, leading to a conclusion that poppet valve could be produced with these findings [23-26].

In this study, the cooling performance of a permanent mold was numerically investigated. Thermal and hydrodynamic behaviors of conformal mold cooling channels and standard cooling channels that could be produced by the DMLS method were analyzed by ANSYS-FLUENT software. Generally, ANSYS-FLUENT program was used for thermal and flow analysis [27-30]. Analyses were made for an engine exhaust valve, which was produced by pouring in permanent mold aluminum alloy material (Al 6061) with a mold. In this work, the casting piece is an exhaust valve of an internal combustion engine. It is mentioned in the study that the $\mathrm{Al} 6061$ alloy automobile engine valve could be made [31]. Therefore, this alloy was chosen as a casting in this study. Temperature distribution and solidification rates based on the time of melting during casting were compared with the original cooling channels.

\section{Numerical modeling}

The metal mold to be produced by the DMLS method of gray cast iron comes from two parts that are symmetrical with respect to each other. As seen in the mold solid model given in Figure 1, the symmetrical mold parts are compactly designed. Original cooling ducts are designed for optimum cooling for cast parts. Due to the symmetry of the designed cooling channels, the effect of heat transfer and solidification of the molten metal was numerically investigated for half of the mold. CFD analyses of the designs using CFD software were carried out to investigate solidification-melting and
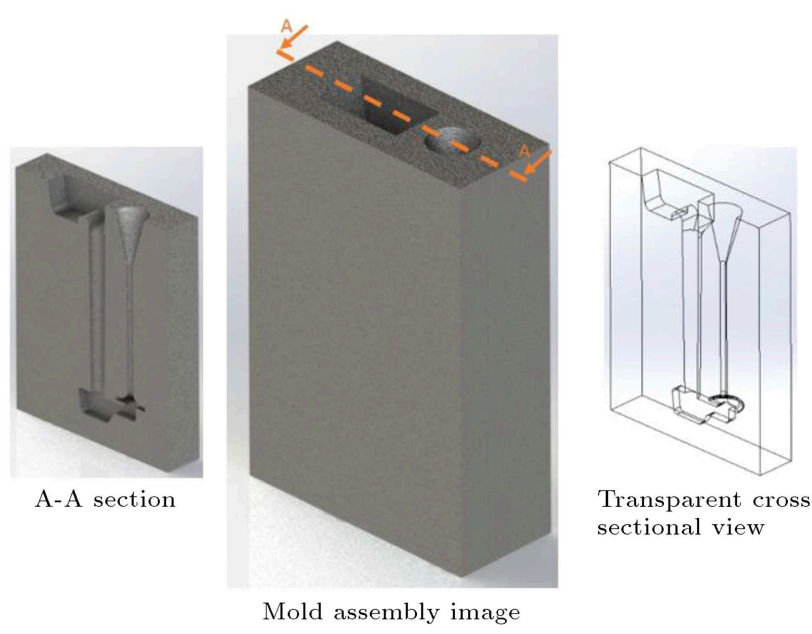

Transparent crosssectional view

Figure 1. Designed metal mold drawing. 
cooling channel thermal and hydrodynamic behaviors, considering the boundary conditions given in Figure 2.

The following equations are used for cooling channels in the numerical analyses.

The continuity, momentum, and energy equations drawn from the background of the program for the flow analyses in the channel are presented below. The equations used by the background program to account for the hydrodynamic behavior of the cooling channels are presented below:

$$
\dot{m}_{\text {oil }}=\rho_{\text {oil }} V A_{c} .
$$

The mass flow of the circulating fluid in the channel is $\dot{m}_{\text {oil }}(\mathrm{kg} / \mathrm{s})$, channel cross-sectional area is $A_{c}$, and mean the average velocity is $V(\mathrm{~m} / \mathrm{s})$.

Hydraulic diameters in the designed cooling channels vary according to being perpendicular to the crosssectional area. The hydraulic diameter, $D_{h}(\mathrm{~m})$, is expressed in Eq. (2):

$$
D_{h}=\frac{4 A_{c}}{P_{w}},
$$

where $A_{c}$ and $P_{w}$ are the cross-sectional area and the wet perimeter, respectively. follows:

For flow in channels, continuity equation is as

$$
\frac{\partial u}{\partial x}+\frac{\partial v}{\partial y}+\frac{\partial w}{\partial z}=0
$$

Momentum equations are shown below:

$$
\begin{aligned}
\rho\left(\frac{\partial u}{\partial t}\right. & \left.+u \frac{\partial u}{\partial x}+v \frac{\partial u}{\partial y}+w \frac{\partial u}{\partial z}\right) \\
& =\mu\left(\frac{\partial^{2} u}{\partial x^{2}}+\frac{\partial^{2} u}{\partial y^{2}}+\frac{\partial^{2} u}{\partial z^{2}}\right)-\frac{\partial P}{\partial x}+\rho g_{x} \\
\rho\left(\frac{\partial v}{\partial t}\right. & \left.+u \frac{\partial v}{\partial x}+v \frac{\partial v}{\partial y}+w \frac{\partial v}{\partial z}\right) \\
& =\mu\left(\frac{\partial^{2} v}{\partial x^{2}}+\frac{\partial^{2} v}{\partial y^{2}}+\frac{\partial^{2} v}{\partial z^{2}}\right)-\frac{\partial P}{\partial y}+\rho g_{y}
\end{aligned}
$$

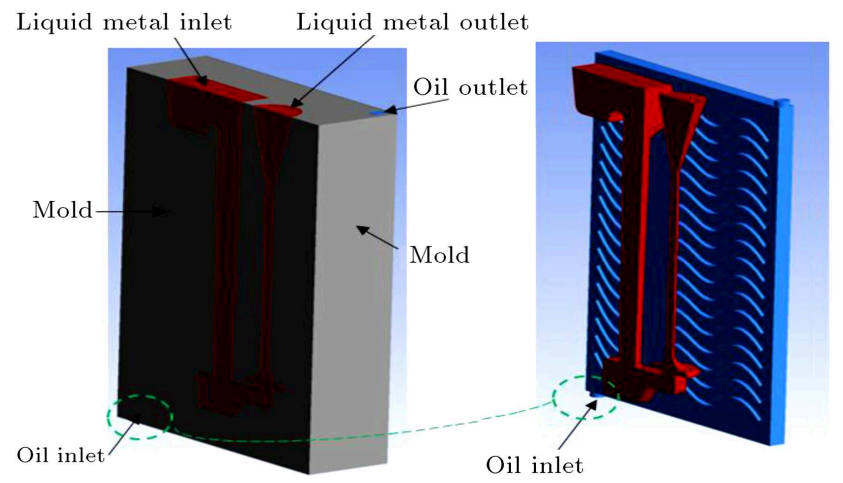

Figure 2. Boundary conditions for cooling channel mold used in analysis.

$$
\begin{aligned}
\rho\left(\frac{\partial w}{\partial t}\right. & \left.+u \frac{\partial w}{\partial x}+v \frac{\partial w}{\partial y}+w \frac{\partial w}{\partial z}\right) \\
& =\mu\left(\frac{\partial^{2} w}{\partial x^{2}}+\frac{\partial^{2} w}{\partial y^{2}}+\frac{\partial^{2} w}{\partial z^{2}}\right) \\
& -\frac{\partial P}{\partial x}+\rho g_{z}
\end{aligned}
$$

where, $g$ is the acceleration of gravity $\left(\mathrm{m} / \mathrm{s}^{2}\right)$.

Energy equation is shown below:

$$
\begin{aligned}
& \rho\left[\frac{\partial\left(C_{p} T\right)}{\partial t}+\frac{\partial\left(C_{p} u T\right)}{\partial x}+\frac{\partial\left(C_{p} v T\right)}{\partial y}+\frac{\partial\left(C_{p} w T\right)}{\partial z}\right] \\
& =\frac{\partial}{\partial x}\left(\lambda \frac{\partial T}{\partial x}\right)+\frac{\partial}{\partial y}\left(\lambda \frac{\partial T}{\partial y}\right)+\frac{\partial}{\partial z}\left(\lambda \frac{\partial T}{\partial z}\right)
\end{aligned}
$$

where $C_{p}$, is the specific heat $(\mathrm{kJ} / \mathrm{kgK})$, and $\lambda$ is the heat transfer coefficient $(\mathrm{W} / \mathrm{mK})$.

After forming the flow volume models of the fluid circulating in the metal mold, the numerical network structure for the CFD analyses was established. For each flow volume model (Standard Channel (SC), Curved Channel (CC), Spherical Fin Channel (SFC), and Plate Type Channel (PTC)), a mesh is placed in the tetra hedral mesh geometry. For these designs, CFD analyses were performed using ANSYS-FLUENT software for designed cooling channels in flow volumes, given in Figure 3. The analyses were carried out to determine transient temperature changes and solidification rates for the valve in different types of cooling channels. In the analyses, the time step was set to 0.001 $\mathrm{s}$, and no significant change was observed in the results at the smaller time step. The numerical model parameters used in the analyses are given in Table 1. Mesh parameters used in simulations are given in Table 2. For designed models, there are 1,134,500, 1,262,000,

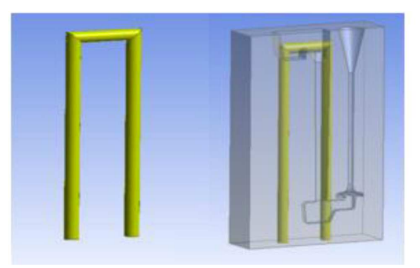

(a)

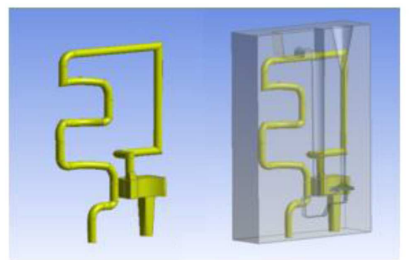

(c)

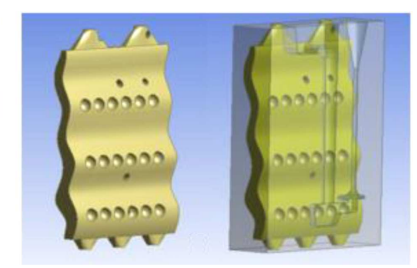

(b)

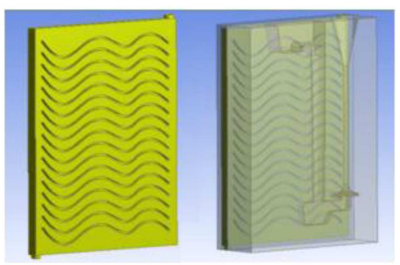

(d)
Figure 3. Designed cooling channels flow volumes: (a) Standard channel, (b) spherical fin channel, (c) curled channel, and (d) plate type channel. 
Table 1. Numerical modelling parameters used in solution.

\begin{tabular}{ll}
\hline Simulation condition & Transient-state \\
Solver type & Pressure based \\
Mesh structure & Tetrahedral \\
Turbulence model & RNG-enhanced wall treatment standard $k-\varepsilon$ turbulence model \\
Wall-turbulence interaction & Standard wall-function \\
Speed-pressure interaction & Coupled algorithm \\
Decomposition method & Second-order upwind \\
\hline
\end{tabular}

Table 2. Mesh parameters used in simulations.

\begin{tabular}{lcccc}
\hline & SC & CC & SFC & P TC \\
\hline Mesh element number & 1134500 & 1262000 & 1294000 & 1428106 \\
Aspect ratio & 1.84 & 1.86 & 1.86 & 1.88 \\
Jakobian ratio & 1.0132 & 1.0 & 1.0 & 1.0 \\
Skewness & 0.22379 & 0.21682 & 0.23578 & 0.26659 \\
\hline
\end{tabular}

Table 3. Thermal properties of heat transfer oil used in numerical analysis.

\begin{tabular}{cccccc}
\hline $\begin{array}{c}\text { Temperature } \\
(\mathbf{K})\end{array}$ & $\begin{array}{c}\text { Density } \\
\left(\mathbf{k g} / \mathbf{m}^{\mathbf{3}}\right)\end{array}$ & $\begin{array}{c}\text { Specific heat } \\
(\mathbf{J} / \mathbf{k g K})\end{array}$ & $\begin{array}{c}\text { Thermal conductivity } \\
(\mathbf{W} / \mathbf{m K})\end{array}$ & $\begin{array}{c}\text { Temperature } \\
(\mathbf{K})\end{array}$ & $\begin{array}{c}\text { Viscosity } \\
(\mathbf{k g} / \mathbf{m s})\end{array}$ \\
\hline 288 & 869 & 1890 & 0.143 & 313 & 0.00307 \\
311 & 855 & 1970 & 0.142 & 373 & 0.00048735 \\
533 & 714 & 2690 & 0.13 & 598 & $4.753 \times 10^{-5}$ \\
559 & 679 & 2880 & 0.128 & - & - \\
\hline
\end{tabular}

Table 4. Thermal properties of Al 6061 used in numerical analysis.

\begin{tabular}{cccccc}
\hline $\begin{array}{c}\text { Temperature } \\
(\mathbf{K})\end{array}$ & $\begin{array}{c}\text { Density } \\
\left(\mathbf{k g} / \mathbf{m}^{\mathbf{3}}\right)\end{array}$ & $\begin{array}{c}\text { Specific heat } \\
(\mathbf{J} / \mathbf{k g K})\end{array}$ & $\begin{array}{c}\text { Thermal conductivity } \\
(\mathbf{W} / \mathbf{m K})\end{array}$ & $\begin{array}{c}\text { Temperature } \\
(\mathbf{K})\end{array}$ & $\begin{array}{c}\text { Viscosity } \\
(\mathbf{k g} / \mathbf{m s})\end{array}$ \\
\hline 298.15 & 2705 & 870 & 192 & 894 & 0.00151 \\
373.15 & 2695 & 950 & 195 & 1073 & 0.001012 \\
473.15 & 2675 & 980 & 203 & & \\
573.15 & 2655 & 1020 & 211 & & \\
673.15 & 2635 & 1060 & 212 & \\
773.15 & 2610 & 1150 & 225 & \\
873.15 & 2590 & 1160 & 200 & & \\
915.15 & 2415 & 1170 & 90 & & \\
973.15 & 2400 & 1170 & 91 & & \\
1073.15 & 2372 & 1170 & 92 & & \\
\hline
\end{tabular}

$1,294,000$, and 1,428,106 mesh elements in $\mathrm{SC}, \mathrm{CC}$, $\mathrm{SFC}$, and PTC, respectively, as can be seen in Table 2. Numerical modeling parameters used in solutions are presented in Table 3. Heat transfer oil specifications of "Petro-Therm" brand name are used as refrigerant in the cooling channels. Thermal properties of heat transfer oil used in numerical analysis are shown in Table 4. Thermal properties of heat transfer oil used in numerical analysis are shown in Table 3. For SC, CC, SFC, and PTC mold, Al 6061 thermal properties are applied in the analysis. Thermal properties of Al 6061 used in numerical analysis are presented in Table 4. 


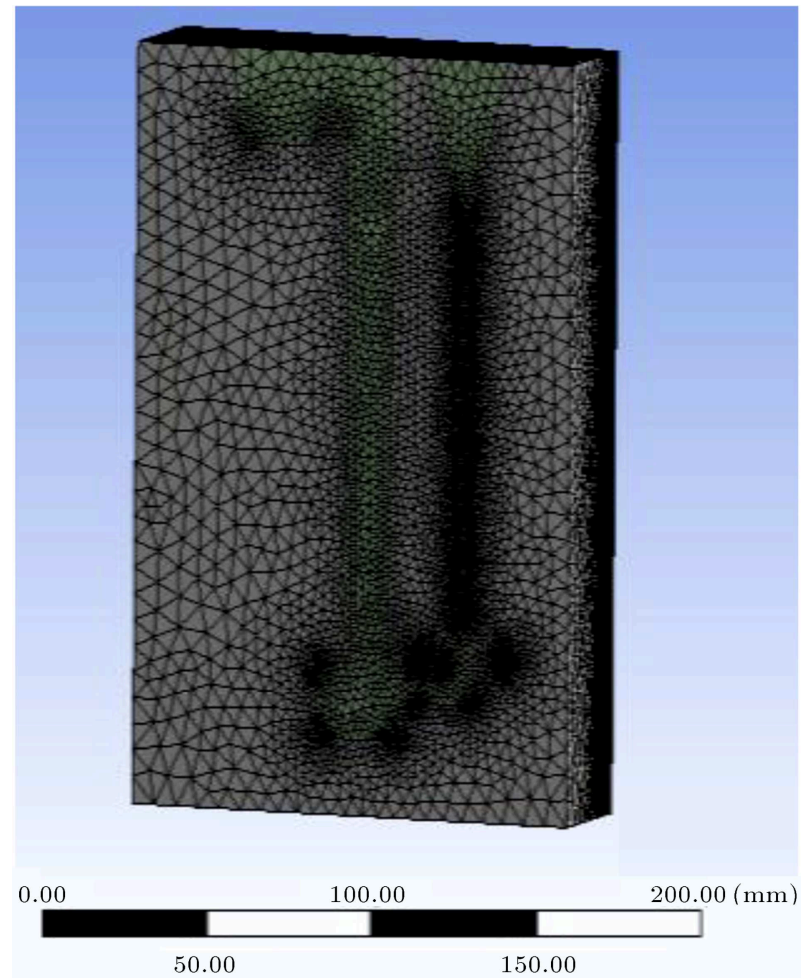

Figure 4. Mesh structure for cooling channel mold used in analysis.

The mass flow is calculated separately for each channel so that the hydraulic velocity at the cooling channels is $1.5 \mathrm{~m} / \mathrm{s}$. The molten metal casting temperature was $973 \mathrm{~K}$. The heat transfer oil was circulated in the cooling channel, and the properties of the Petro-Therm commercial product were added. Mesh structure for the cooling channel mold used in the analysis is shown in Figure 4.

\section{Numerical results}

Results of numerical analysis at the 1st, 3rd, and 5th seconds are obtained in the CFD-POST 16.1 program. In the analyses made, the symmetry of all of the compact molds was obtained for 4 different cooling channel designs with a three-dimensional temperature distribution of the cooling duct, metal mold, and molten metal (Figure 5). Again, the molten metal solidification rate was similarly compared. Figure 6 shows the variation of the temperature distributions along the valve axis based on the valve height for the four different types of the cooling channel after the 1st, $3 \mathrm{rd}$, and 5 th seconds of casting.

At the end of $1 \mathrm{~s}$, the temperature between the valve head (disc) and the valve stem is noteworthy. After $0.02 \mathrm{~m}$ of valve height, the temperature towards the stem decreases sharply. Temperature drop SFC is the largest in the type channel, while, at least, in the PTC, the fixed temperature zone for the 4-channel
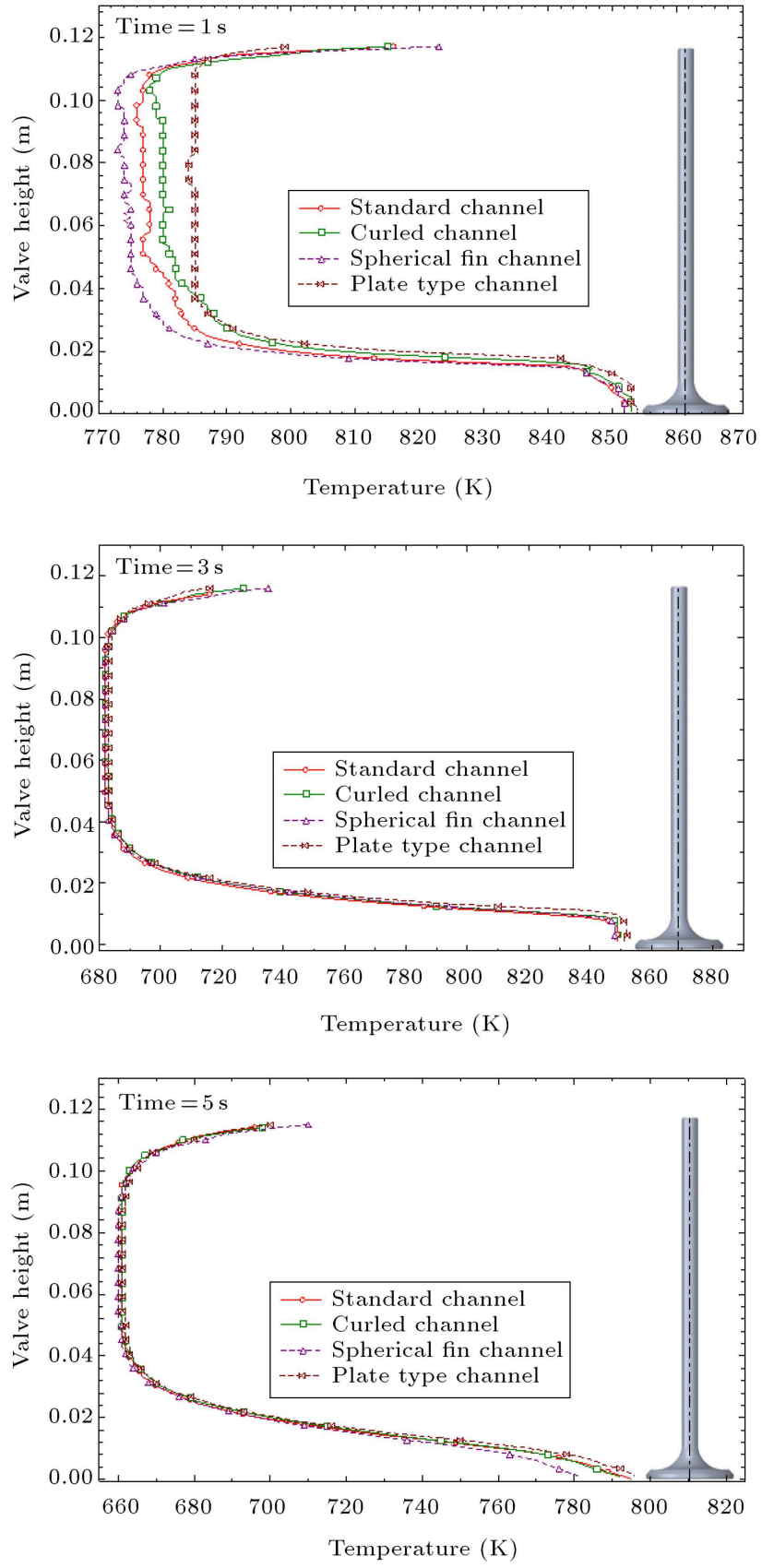

Figure 5. Temperature distribution along the valve axis after 1st, 3rd, and 5th seconds from casting for SC, CC, SFC, and PTC type cooling channels.

design on the stem ranges from $0.02 \mathrm{~m}$ to 0.11 . $\mathrm{m}$. After $3 \mathrm{~s}$, it is observed that the passage of the decreasing temperature from the discrete to the stem is smoother with respect to the valve height from $0.01 \mathrm{~m}$ to $0.04 \mathrm{~m}$ compared to those at $1 \mathrm{~s}$. Although there is no significant difference in temperature change for four different types of channels, the constant temperature zone in the stem is shorter than $0.04 \mathrm{~m}$ to $0.1 \mathrm{~m}$ in comparison to that at $1 \mathrm{~s}$. At the end of $5 \mathrm{~s}$, the temperature transitions towards the disc stalk seem to be softer than those at $3 \mathrm{~s}$. After $5 \mathrm{~s}$, the lowest temperature in the 


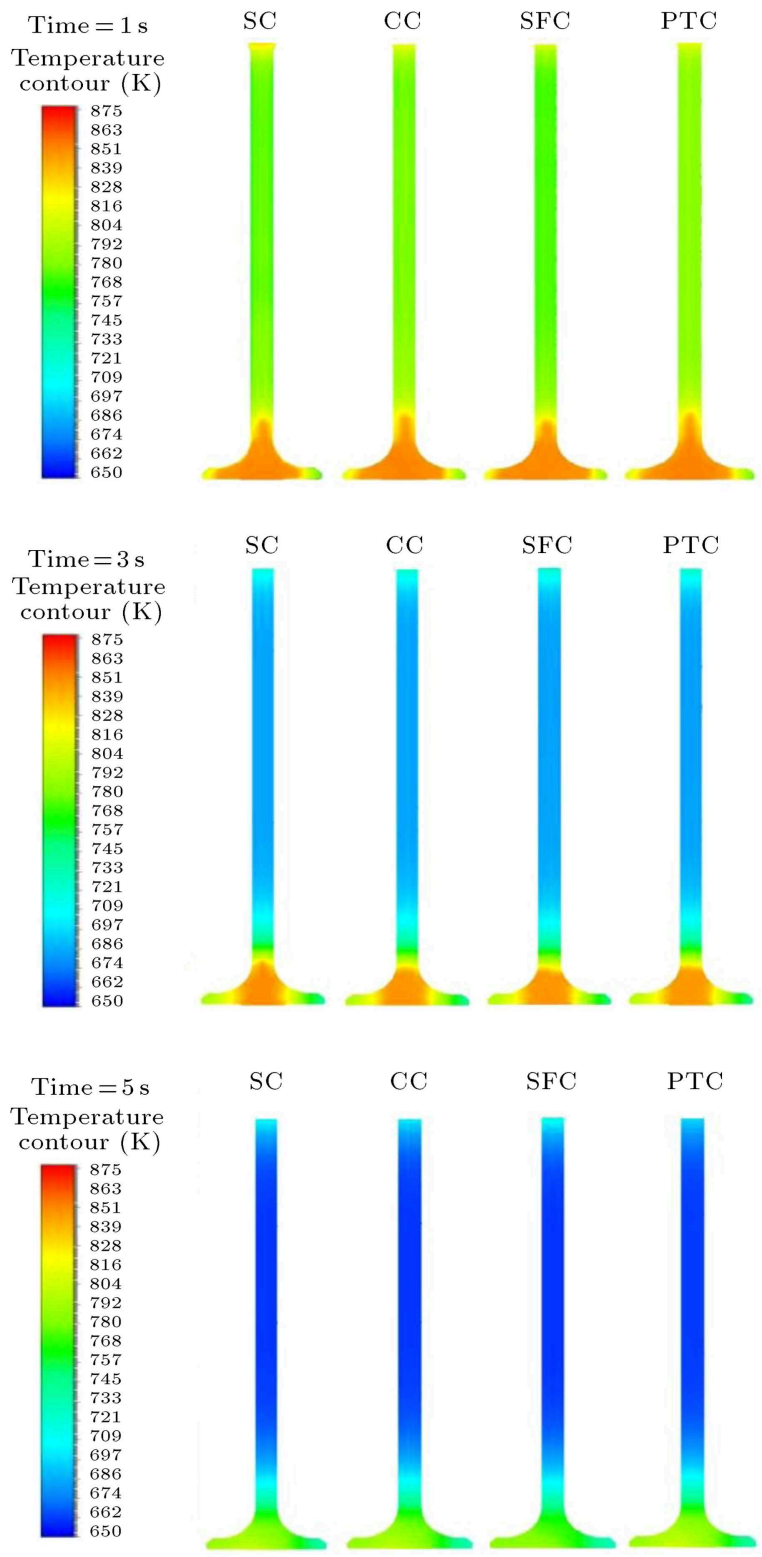

Figure 6. Temperature contours throughout the valve after 1st, 3rd, and 5th seconds after casting for SC, CC, SFC, and PTC type cooling channels.

disc for cooling with the SFC type duct was obtained as $780 \mathrm{~K}$. After $0.02 \mathrm{~m}$, there is no significant difference in temperature variations for 4 different types of channels along the central axis of the valve.

Figure 7 shows the variation of the liquid fractions along the valve axis based on the valve height after 1st, $3 \mathrm{rd}$, and 5 th seconds of casting for 4 different types of cooling ducts. At the end of $1 \mathrm{~s}$, solidification in the SFC type cooling channel for the disc entrance area (gate) in the runner is the earliest, while the liquid fraction 1 is observed in the PTC. The same is true for the mold vent. The liquid fraction data zone center is extended. Complete solidification has been achieved for all channel types at the handle between $0.02 \mathrm{~m}$ and
$0.13 \mathrm{~m}$. At the end of $3 \mathrm{~s}$, the valve disc corresponds to the center axis of 0 to $0.02 \mathrm{~m}$, while the liquid fraction is the least for the SFC channel mold, while, for PTC, it is the largest. Solidification is complete when the center axis is between $0.02 \mathrm{~m}$ and $0.14 \mathrm{~m}$. For SC, $\mathrm{CC}$, and SFC type cooling channels in the airway, the liquid fraction is close to $0.5-0.6$, while it reaches up to 1 for the PTC type channel. For all cooling channel designs, the solidification was fully realized for the valve after $5 \mathrm{~s}$. At the end of $5 \mathrm{~s}$, solidification in the PTC type cooling channel mold could reach up to $0.14 \mathrm{~m}$ in other cooling channels, with the center axis extending approximately to $0.15 \mathrm{~m}$. However, in proximity to the ventilation pit, this situation is reversed, and $\mathrm{SC}$, $\mathrm{CC}$, and SFC type cooling duct molds are less than the liquid fraction PTC. In addition, among SC, CC, and PTC grooved molds, the SFC type channel mold has the least liquid fraction.

\section{Conclusions}

The study investigated the effect of different types of cooling channels on the solidification rate and heat transfer for a material to be manufactured from $\mathrm{Al}$ alloy in a permanent mold. Results of the transient numerical analysis were achieved at the 1st, 3rd, and 5 th seconds. The effect of cooling performance between cooling channels on solidification could be seen in analyses made up until the 5 th seconds. Because model geometries are complex, the analysis takes a very long time to carry out, which is why the analyses could be carried out until the 5 th seconds.

According to the temperature distributions after $1 \mathrm{~s}$ from the casting, the SFC type channel can cool faster than the other channels. However, there is no significant difference between the originally designed geometries (CC, SFC, PTC) for the 3rd type according to the cooling channel (SC) of the standard type. The temperature in the SFC channel for the base temperature of the base of the valve at the 5 th second was observed to be lower than that in the other channels.

According to the numerical results of the solidification process, the solidification rate in the SFC-type channel design was higher than that in other designs. Herein, the CC-type channel design was considered for the conformal cooling of the lately stiffened parts according to the design of the cast part. However, according to the results of numerical analysis, there is no significant difference between $\mathrm{CC}$ and SC. SC outperformed CC and PTC at the 1st-5th seconds for casting in terms of better cooling. At the 5th second, solidification for the valve, which is the casting part, was finished. Because the analyses were very complex and took a long time, they could be run up to 5 seconds. In this study, the influence of the cooling channels on 

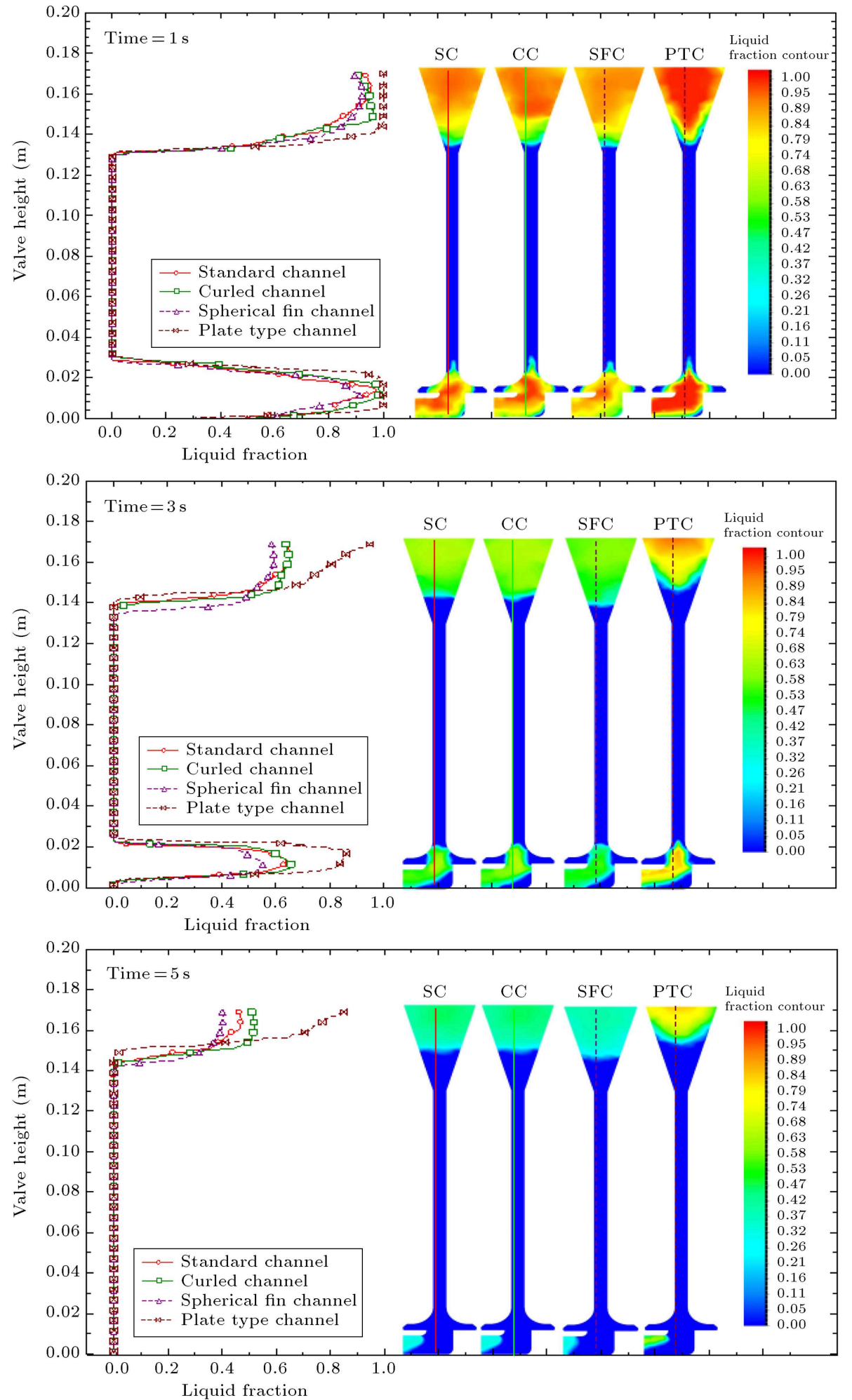

Figure 7. Liquid fraction along the valve axis after 1st, 3rd, and 5th seconds for casting for SC, CC, SFC, and PTC type cooling channels.

the casting part was investigated. The temperature distribution for the mold can be considered separately in further studies. The importance of CFD analysis is emphasized while designing cooling channels in a metal mold to be produced by joint manufacturing.
Numerical analyses should be compared with realworld applications in the subsequent studies, and the specific cooling channels to be produced by SLM (Selective Laser Melting) should also be experimentally examined. 


\section{References}

1. Hsu, F.H., Wang, K., Huang, C.T., and Chang, R.Y. "Investigation on conformal cooling system design in injection molding", Advances in Production Engineering \& Management, 8(2), pp. 107-115 (2013).

2. Hongjun, L., Zitian, F., Naiyu, H., and Xuanpu, D. "A note on rapid manufacturing process of metallic parts based on SLS plastic prototype", Journal of Materials Processing Technology, 142, pp. 710-713 (2003).

3. Ferreira, J.C. and Mateus, A. "Studies of rapid soft tooling with conformal cooling channels for plastic injection moulding", Journal of Materials Processing Technology, 142, pp. 508-516 (2003).

4. Deckers, J., Meyers, S., Kruth, J.P., and Vleugels, J. "Direct selective laser sintering/melting of high density alumina powder layers at elevated temperatures", Physics Procedia, 56, pp. 117-124 (2014).

5. Dalgarno, K.W. and Stewart, T.D. "Manufacture of production injection mould tooling incorporating conformal cooling channels via indirect selective laser sintering", Proceeding of the Institution of Mechanical Engineers, 215(B), pp. 1323-1332 (2001).

6. Wang, Y., Yu, K.M., and Wang, C.C.L. "Spiral and conformal cooling in plastic injection molding", Computer-Aided Design, 63, pp. 1-11 (2015).

7. Xia, C., Fu, F., Lai, J., Yao, X., and Chen, Z. "Conjugate heat transfer in fractal tree-like channels network heat sink for high-speed motorized spindle cooling", Applied Thermal Engineering, 90, pp. 1032$1042(2015)$.

8. Hu, P., He, B., and Ying, L. "Numerical investigation on cooling performance of hot stamping tool with various channel designs", Applied Thermal Engineering, 96, pp. 338-351 (2016).

9. Wang, H.L., Wu, H.C., Wang, S.K., Hung, T.C., and Yang, R.J. "A study of mini-channel thermal module design for achieving high stability and high capability in electronic cooling", Applied Thermal Engineering, 51, pp. 1144-1153 (2013).

10. Vojnová, E. "The benefits of a conforming cooling systems the molds in injection moulding process", Procedia Engineering, 149, pp. 535-543 (2016).

11. Venkatesh, G.Y. Ravi, K., and Raghavendra, G. "Comparison of straight line to conformal cooling channel in injection molding", Materials Today: Proceedings, 4(2), pp. 1167-1173 (2017).

12. Jahan, A.S. and Mounayri, H. "Optimal conformal cooling channels in 3D printed dies for plastic injection molding", Procedia Manufacturing, 5, pp. 888-900 (2016).

13. Venkatesh, G.Y. and Kumar, R. "Thermal analysis for conformal cooling channel", 5th International Conference of Materials Processing and Characterization (ICMPC 2016), Materials Today: Proceedings, 4, pp. 2592-2598 (2017).
14. Zehtabiyan, R.N., Damirci, D.S., Fazel, Z.M.H., and Saffar, A.M. "Generalized heat transfer and entropy generation of stratified air-water flow in entrance of a mini-channel", Scientia Iranica, B, 24(5), pp. 24062417 (2017).

15. Nouri, B.A. and Seyyed-Hashemi, M.H. "Numerical analysis of thermally developing turbulent flow in partially filled porous pipes", Scientia Iranica, B, 22(3), pp. 835-843 (2015).

16. Imran, A.A., Nabeel, S.M., and Hayder, M.J. "Numerical and experimental investigation of heat transfer in liquid cooling serpentine mini-channel heat sink with different new configuration models", Thermal Science and Engineering Progress, 6, pp. 128-139 (2018).

17. Park, H. and Dang, X.P. "Development of a smart plastic injection mold with conformal cooling channels", Procedia Manufacturing, 10, pp. 48-59 (2017).

18. Sachs, E., Wylonis, E., Allen, S., Cima, M., and Guo, H. "Production of injection moulding tooling with conformal cooling channels using the three dimensional printing process", Polymer Engineering and Science, 40(5), pp. 1237-1247 (2000).

19. Eimsa-ard, K. and Wannisorn, K. "Conformal bubbler cooling for molds by metal deposition process", Computer-Aided Design, 69, pp. 126-133 (2015).

20. Hölker, R., Haase, M., Khalifa, N.B., and Takkaya, A.E. "Hot extrusion dies with conformal cooling channels produced by additive manufacturing", Aluminum Two Thousand World Congress and International Conference on Extrusion and Benchmark ICEB, pp. 4838-4846 (2015).

21. Koller, M., Walter, H., and Hameter, M. "Transient numerical simulation of the melting and solidification behavior of NaNO3 using a wire matrix for enhancing of the heat transfer", Energies, 9, p. 205 (2016).

22. Kumar Koli, D., Agnihotri, G., and Purohit, R. "Advanced aluminium matrix composite: the critical need of automotive and aerospace engineering fields", Materials Today: Proceeding, 2, pp. 3032-3041 (2015).

23. Furumoto, T., Ueda, T., Amino, T., Ksunoki, D., Hosokowa, A., and Tanaka, T. "Finishing performance of cooling channel with face protuberance inside the molding die", Journal of Material Processing Technology, 212, pp. 2154-2160 (2012). DOI: 10.1016/j.jmatprotec.2012.05.016

24. Ozsarac, U., Işik, Ş., Varol, F., Emin Unat, M., Özdemir, C., and Aslanlar, S. "Investigation of tensile properties of aluminum $6082-\mathrm{T} 6$ alloys joined by cold metal transfer method by using different working time", Acta Physica Polonica A, 132(3), p. 705 (2017).

25. Djendel, M., Allaoui, O., and Boubaaya, R. "Characterization of alumina-titania coatings produced by atmospheric plasma spraying on 304 SS steel", Acta Physica Polonica A, 132(3), p. 538 (2017).

26. Aktas, B. , Balak, V., and Carboga, C. "Dry sliding wear behavior of boron-doped AISI 1020 steels", Acta Physica Polonica A, 132(3), p. 455 (2017). 
27. Ipek, O., Kan, M., and Gurel, B. "Examination of different heat exchangers and the thermal activities of different designs", Acta Physica Polonica A, 132(3), pp. 580-583 (2017).

28. Karaçall, Ö. "Computational material analysis of structural and hemodynamic model of coronary stent by CFD/FEA in computer aided mechanical engineering approach", Acta Physica Polonica A, 130(1), p. 249 (2016).

29. Kan, M., Ipek, O., and Gurel, B. "Plate heat exchangers as a compact design and optimization of different channel angles", Acta Physica Polonica A, 128(2B), pp. B-49_B-52 (2015).

30. FLUENT Manual, Chapter 21: Modeling Solidification and Melting; ANSYS, Inc.: Canonsburg, PA, USA (2001).

31. Patel, D.R. and Patel, N.S. "Development of Al-SiC MMCs for making valves", International Journal of Advanced Research and Innovative Ideas in Education, 2(3) pp. 2619-2628 (2016).

\section{Biographies}

Osman Ípek is a Professor in Mechanical Engineering at the Department of Mechanical Engineering at Süleyman Demirel University. He received his BSc and MSc degrees from Akdeniz University, Antalya, Turkey in 1986 and 1988, respectively. His main research interests focus on heat exchangers, heat transfer enhancement, fluid mechanics, thermodynamics, and energy.
Ali Bolattürk is a Professor at the Department of Mechanical Engineering at Süleyman Demirel University, Isparta, Turkey. He received his BSc and MSc degrees in Mechanical Engineering from Akdeniz University in 1990 and 1992, respectively. He has been teaching since then. His research interests are thermodynamics, heat transfer, exergy, and exergoeconomic analysis of the thermodynamic systems.

Mehmet Kan received his BSc degree in Mechanical Engineering at Mustafa Kemal University in 2009 and MSc degrees in Mechanical Engineering from Süleyman Demirel University in 2014. He is currently a PhD Candidate in Mechanical Engineering and a Research Assistant at Süleyman Demirel University. His research interests are heat transfer enhancement, fluid mechanics, thermodynamics, energy, Computational Fluid Dynamics (CFD), and solidificationmelting analysis.

Karani Kurtuluş received his BSc and MSc degrees from Mechanical Engineering at Süleyman Demirel University in 2011 and 2014, respectively. $\mathrm{He}$ is currently a PhD Candidate in Mechanical Engineering and a Research Assistant at Süleyman Demirel University. His research interests include heat transfer enhancement, exergy and exergoeconomic analysis of the thermodynamic systems, Computational Fluid Dynamics (CFD), and solidification-melting analysis. 